DEPARTMENT OF COMMERCE

U. S. Gov't

No. 246

BUREAU OF STANDARDS

George K. Burgess, Director

CIRCULAR OF THE BUREAU OF STANDARDS, No. 193

[Issued January 9, I925]

\title{
UNITED STATES GOVERNMENT MASTER SPECIFICATION FOR LIQUID SOAP (FOR LAUNDRY USE)
}

\section{FEDERAL SPECIFICATIONS BOARD SPECIFICATION No. 246}

This specification was officially promulgated by the Federal Specifications Board on November 5, 1924, for the use of the Departments and Independent Establishments of the Government in the purchase of liquid soap (for laundry use).

\section{CONTENTS}

I. Grade Page

II. Material and workmanship_-_-_-_-_-_-_-_-_-_-_---_--- 1

III. General requirements_-_-_-_-_-_-

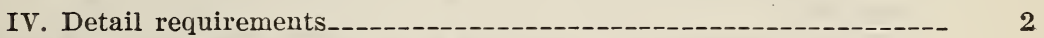

V. Methods of inspection and testing

1. Sampling

2. Methods of testing

3. Reagents --

VI. Packing and marking --_-_- 5

VII. Additional information

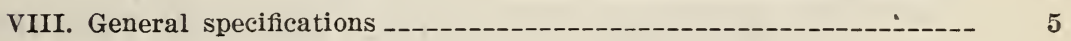

\section{GRADE}

Liquid soap for laundry use shall be of one grade only, as hereinafter described.

\section{MATERIAL AND WORKMANSHIP}

Liquid soap for laundry use shall be made of high-grade materials and shall be entirely satisfactory for the purpose intended.

\section{GENERAL REQUIREMENTS}

The soap desired under this specification is a clear solution of pure potash (or potash and soda) soap with or without glycerol or $23435^{\circ}-25$ 
alcohol and containing not less than 12 per cent by weight of a volatile organic solvent or a mixture of such solvents. It shall yield a clear solution on mixing with soft water, shall quickly form a satisfactory lather, shall have no injurious effect and leave no objectionable odor on fabrics. Materials washed with this soap shall have, after drying, a soft feel and not appear more boardy or stıtf than when washed with soft water.

\section{DETAIL REQUIREMENTS}

Failure to meet any of the following requirements will be cause for rejection:

1. The material shall be a clear solution, shall yield a clear, homogeneous solution on mixing with soft water, shall quickly form a satisfactory lather, and shall leave no objectionable odor on fabric.

2. Total anhydrous soap shall be not less than the equivalent of 24 per cent potash soap.

3. Total matter insoluble in alcohol shall not exceed 0.5 per cent.

4. Free alkali, calculated as potassium hydroxide $(\mathrm{KOH})$, shall not exceed 0.05 per cent.

5. Chloride, calculated as potassium chloride $(\mathrm{KCl})$, shall not exceed 0.3 per cent.

6. Total matter insoluble in water shall not exceed 0.1 per cent.

7. Volatile organic solvent shall be not less than 12 per cent.

8. All constituents shall be calculated on the basis of the original sample.

9. Washing test.-Fabric washed with the liquid soap shall show no more shrinkage or felting than occurs with similar fabric washed with soft water at the same temperature. Colored materials when washed with this soap shall not fade more than when washed the same number of times at the same temperature with soft water alone.

\section{METHODS OF INSPECTION AND TESTING}

\section{SAMPLING}

(a) No samples shall be submitted with bids.

(b) Samples of not less than one-half pint shall be taken at random from not less than 1 per cent of the rendors' shipping containers, provided such containers contain not less than 10 gallons each. In case of smaller containers a sample of not less than one-half pint shall be taken at random from each lot of containers totaling not to exceed 1,000 gallons. The total sample shall in all cases consist of not less than three portions of one-half pint each taken at random from separate containers. Before drawing the sample from the container selected the contents of the container shall be thoroughly agitated. The inspector shall thoroughly mix the samples drawn, place 
in clean, dry cans or bottles, which shall be completely filled and securely stoppered with clean corks or caps, seal, mark, and send to the laboratory for test. The seller shall have the option of being represented at the time of sampling and when he so requests shall be furnished with a duplicate sample.

\section{METHODS OF TESTING}

(a) Preparatiox of Sample-No preparation of the sample, other than thorough mixing, is necessary unless it is received during very cold weather, when it should be allowed to stand at least one hour after it has warmed up to room temperature $\left(20\right.$ to $30^{\circ} \mathrm{C}$.) before it is noted whether it is clear, miscible with soft water, and forms a satisfactory lather.

When a determination shows nonconformity with the specification, a duplicate shall be run.

(b) Total Anhydrous Soap.-Dissolve $10 \mathrm{~g}$ of the sample in 100 cc of water in a $250 \mathrm{cc}$ Erlenmeyer flask. When solution is complete, add dilute sulphuric acid in slight excess, insert a small funnel in the neck of the flask, and heat the flask at a temperature not exceeding $60^{\circ} \mathrm{C}$. until the fatty acids separate as a clear layer. Transfer to a separatory funnel, draw off the acid layer into a second separatory funnel, and shake the acid aqueous liquid with two $20 \mathrm{cc}$ portions of ethyl ether. Dissolve the fatty acids in the ether used for washing the aqueous liquid and shake with $10 \mathrm{cc}$ portions of water until they are no longer acid to methyl orange. Unite the water portions used for washing and shake with $20 \mathrm{cc}$ of ether, wash this ether until the wash water is neutral to methyl orange. Unite the ether solutions (if necessary, filter, washing the paper with ether) in a suitable weighed vessel, add $100 \mathrm{cc}$ of neutral alcohol free from carbon dioxide, add phenolphthalein and titrate to exact neutrality with standard sodium hydroxide solution. Evaporate off the alcohol, dry to constant weight in an inert atmosphere at a temperature not exceeding $105^{\circ} \mathrm{C}$, and calculate the percentage of soda soap. This soap includes any mineral oil and neutral fat, which, if determined separately, must be deducted from the result to obtain the true soap. Calculate the combined sodium oxide $\left(\mathrm{Na}_{2} \mathrm{O}\right)$ and deduct from the weight of soda soap to give the anhydrides. Proper calculation must be made to reduce to potassium oxide $\left(\mathrm{K}_{2} \mathrm{O}\right)$ or the titration made directly with standard potassium hydroxide solution, unless it is known that the soap is not a potash soap. In case the soap shors an excess of free acid, proper corrections must be made in calculating the combined alkali in the original soap. (A blank test should be made on the sodium or potassium hydroxide solution for neutral salts and the proper corrections made if necessary.) 
(c) Total Matter Insoluble ix Alcohol, Free Alkali, or Free Acin.-(1) Matter insoluble in alcohol.-Digest hot a $10 \mathrm{~g}$ sample with 200 cc of freshly boiled neutral ethyl alcohol (94 per cent or higher). Filter through a counterpoised filter paper neutral to phenolphthalein, or a weighed Gooch crucible with suction, protecting the solution during the operation from carbon dioxide and other acid fumes. Wash the residue on the paper or in the crucible with hot neutral alcohol until free from soap. Dry the filter paper or crucible and residue at 100 to $105^{\circ} \mathrm{C}$. for three hours, cool, and weigh the total matter insoluble in alcohol.

(2) Free alkali or free acid.-Titrate the filtrate from the above, using phenolphthalein as indicator, with standard acid or alkali solution, and calculate the alkalinity to potassium hydroxide or acidity to oleic acid.

(3) Matter insoluble in water.-Proceed as in the determination of matter insoluble in alcohol. After filtering and thoroughly washing the residue, extract it with water at $60^{\circ} \mathrm{C}$. and wash the filter thoroughly. (When the matter insoluble in water is all inorganic, boiling water may be used for the extraction and washing.) Dry the filter and residue at 100 to $105^{\circ} \mathrm{C}$. for three hours, cool, and weigh the matter insoluble in water. The nature of this may be determined by further examination.

(d) Chloride.-Dissolve $10 \mathrm{~g}$ of the sample in $300 \mathrm{cc}$ of water, boiling if necessary to effect solution of all soluble matter. Add an excess of neutral chlorine-free magnesium nitrate solution (about 25 cc of a 20 per cent $\mathrm{Mg}\left(\mathrm{NO}_{3}\right)_{2} \cdot 6 \mathrm{H}_{2} \mathrm{O}$ solution). Without cooling or filtering titrate with standard silver nitrate solution, using potassium chromate as indicator. Calculate as potassium chloride.

(e) Volatile Solient.-Decompose $100 \mathrm{~g}$ of the sample in a $500 \mathrm{cc}$ round-bottom distillation flask with a slight excess of calcium chloride solution. Connect to a suitable water-cooled condenser, heat with an open flame and distill until there is no further increase in the volume of the organic distillate which is received in a graduated cylinder. Stopper the cylinder and allow to stand 8 to 12 hours; read the volume of the organic distillate and separate it from the water. Determine the specific gravity of the organic distillate and calculate the percentage by weight.

(f) Actiox on Fabrics.-(1) Shrinkage.-Wash similar pieces of goods with the soap and with soft water, and dry under similar conditions. Take measurements before and after the washing tests and express the results either in square inches or in lineal dimensions after selecting the most important dimension, such as trunk measurement on underwear.

(2) Fastness of dyes.-Submit the goods to a five-hour washing test in which the temperature of the solution is $54.5^{\circ} \mathrm{C}$. $\left(130^{\circ} \mathrm{F}\right.$.) 
with a fair level of water in the wash wheel. Run a similar test with soft water at $54.5^{\circ} \mathrm{C}$.

\section{REAGENTS}

(a) Standard Sodidm Hrdroxide Soldtion.-0.25 N, or about $10 \mathrm{~g}$ sodium hydroxide dissolved in water and diluted to 1 liter. Standardize against Bureau of Standards benzoic acid.

(b) Standard Stlphuric Acid.-0.5 N, or about $25.8 \mathrm{~g}$ strong sulphuric acid (specific gravity=1.84) diluted with water to 1 liter. Standardize against standard sodium hydroxide solution $\mathrm{V}, 3,(a)$.

(c) Standard Alcoholic Potassidur Hrdroxide Solution.-0.25 $\mathrm{N}$, or about $14 \mathrm{~g}$ of potassium hydroxide dissolved in neutral ethyl alcohol (94 per cent or higher) and diluted to 1 liter with alcohol. Standardize against Bureau of Standards benzoic acid.

(d) Standard Alcoholic Sodium Hydroxide Soldtion.-Same as (a) excepting that (94 per cent or higher) ethyl alcohol is used instead of water. Standardize against benzoic acid.

(e) Standard Silver Nitrate Solution.-0.10 N, or about $17 \mathrm{~g}$ of silver nitrate dissolved in water and diluted to 1 liter. Standardize against chemically pure sodium chloride.

(f) Potassium Chromate Solution.-Dissolve $10 \mathrm{~g}$ of chloridefree potassium chromate in $100 \mathrm{cc}$ of water.

\section{PACKING AND MARKING}

No details.

\section{ADDITIONAL INFORMATION}

Basis of Purchase.-The material shall be purchased either by weight or volume (231 cubic inches to the gallon).

\section{GENERAL SPECIFICATIONS}

No details.

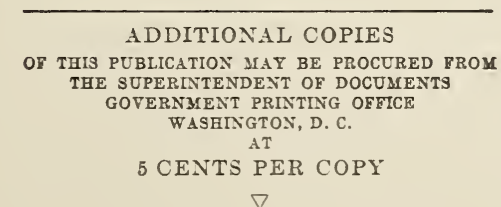







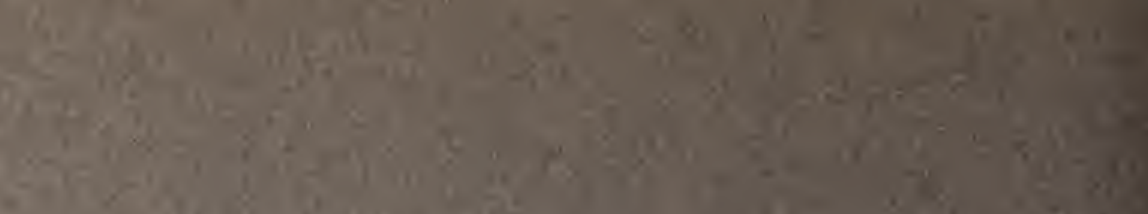

6.6

\section{$\sin ^{2}$}

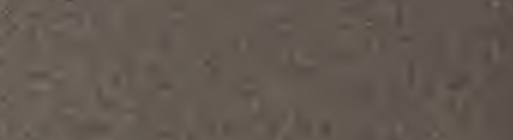

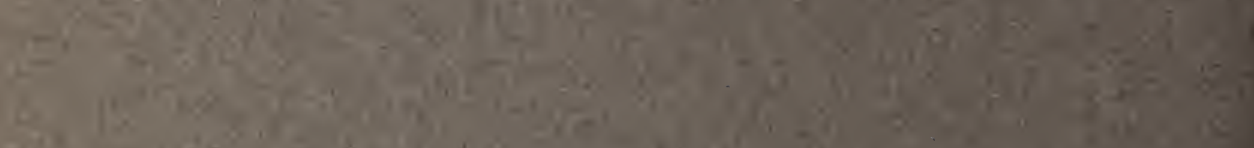

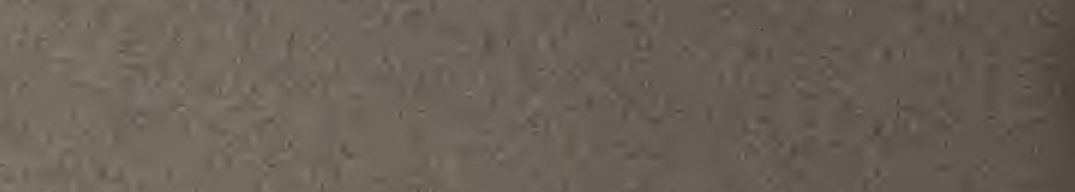

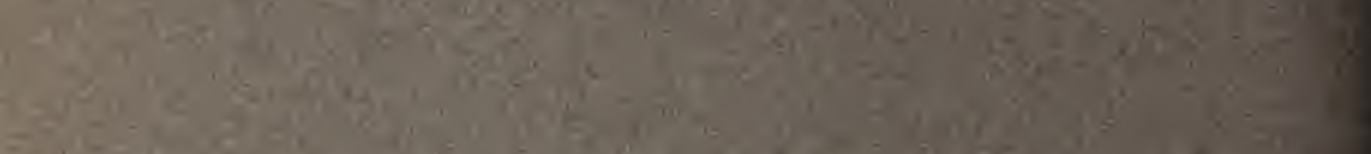

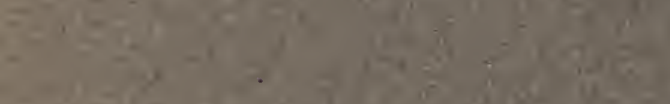

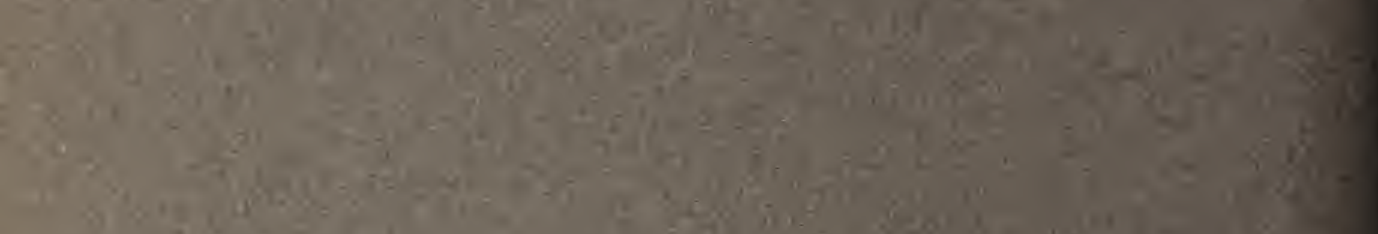

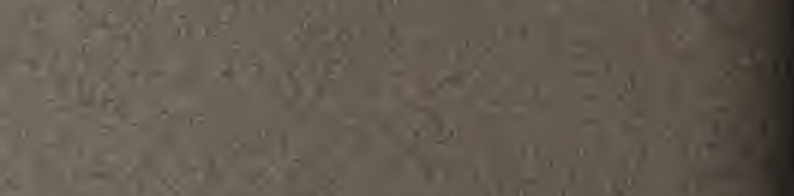
$-190^{2}$ in: 